\title{
A interdisciplinaridade e o ensino do design
}

\author{
Interdisciplinarity and the Design teaching
}

\author{
FONTOURA, Antonio Martiniano; Doutor; PUCPR | UFPR | UTFPR \\ amfont@matrix.com.br ou antonio.fontoura@pucpr.br
}

\begin{abstract}
Resumo
Este artigo é um estudo teórico que buscou conceituar a interdisciplinaridade, o especialismo e o generalismo e caracterizar o Design como uma atividade interdisciplinar, cuja formação pro-fissional nas suas diversas modalidades (gráfico, moda, produto, digital, etc.), deve ser sem-pre orien-tada por uma visão holística e integradora.
\end{abstract}

Palavras Chave: Design. Interdisciplinaridade. Ensino. Educação.

\begin{abstract}
This paper is a theoretical study that aims to define interdisciplinarity, specialism and generalism and to characterize the Design as an interdisciplinary activity whose professional training, in its different modalities (graphic, fashion, product, digital, etc.), should always be guided by a holistic and integrative viewpoint.
\end{abstract}

Keywords: Design. Interdisciplinarity. Teaching. Education.

\section{Introdução}

Ofinal do século passado apresentou-se marcado pela maneira frágil que o conhecimento e o saber se organizaram. Constituíram esquemas disciplinares importantes, mas que não lhes restaram muitas alternativas de desenvolvimento. Foram importantes, pois conduziram por muito tempo a forma de pensar e de produzir os conhecimentos da humanidade, assim não se pode ignorá-los.

Em nenhum outro momento da história o ser humano teve a sua sobrevivência tão diante ameaçada na face da terra. Os conhecimentos científicos e as tecnologias contemporâneas parecem não garantir a existência da espécie no futuro. O homem é capaz de ir à Lua, enviar satélites construídos com alta tecnologia a planetas distantes, construir telescópios poderosíssimos, criar sistemas de comunicação complexos, mas ainda não é capaz de curar prontamente uma "gripe" ou, então, de evitar óbitos causados por doenças sérias, como a AIDS ou combater o câncer de maneira eficaz.

As preocupações com as questões relacionadas à sustentabilidade econômica, social e ambiental estão cada vez mais presentes nas pautas das discussões internacionais, tendo em vista os limitados recursos naturais do planeta. A velocidade com que as tecnologias se desenvolvem e se substituem, o aumento da quantidade de informações e de conhecimentos e da velocidade com que elas se multiplicam, o crescimento populacional - de 3 para 7 bilhões de habitantes no mundo em 30 anos - e o surgimento de novas ocupações em substituição a outras obsoletas pelos novos tempos, são fenômenos que vêm promovendo transformações

Projética Revista Científica de Design I Universidade Estadual de Londrina I V.2 I N.2 I Dezembro 2011 
A interdisciplinaridade e o ensino do design

radicais na maneira de ser e de viver humano. Os sociólogos e os cientistas políticos presenciam estarrecidos os acontecimentos e a maneira como o mundo vem se transformando. As mudanças aos poucos rompem com todos os modelos ideológicos e políticos que perduraram até então.

Este breve relato caracterizou em parte, uma das origens da crise que o início do novo milênio reservou à humanidade, e evidencia a necessidade de se buscar outros modelos que permitam superar as formas tradicionais de pensar, emolduradas nos limites da disciplinaridade (1) - pretensa organizadora do conhecimento.

Intelectuais, sociólogos, psicólogos, pedagogos e filósofos contemporâneos demonstram estar dispostos a discutir com seriedade, as barreiras sociais, políticas, econômicas e culturais, ao retomar o questionamento das formas de reprodução, apropriação e construção dos conhecimentos, do poder que a posse e a manipulação de tais conhecimentos outorgam a quem os detém e dos processos de dominação.

\section{A interdisciplinaridade}

A interdisciplinaridade (2) representa uma possibilidade de reflexão sobre a pertinência ou não da noção de disciplina e representa, também, uma possibilidade de ação comprometida com a continuidade da democracia. Quando questões como estas são evocadas, emerge, quase que por força do destino, uma nova forma de humanismo em oposição ao especialismo vigente até então.

A interdisciplinaridade, como questão gnosiológica, surgiu no final do século passado, pela necessidade de dar uma resposta à fragmentação causada por uma epistemologia de cunho positivista. As ciências haviam-se dividido em muitas disciplinas e a interdisciplinaridade restabelecia, pelo menos, um diálogo entre elas, embora não resgatasse ainda a unidade e a totalidade do saber (INSTITUTO PAULO FREIRE, 2011).

A discussão promovida em torno da interdisciplinaridade envolve, como princípio dela mesma, todas as áreas do conhecimento, incluindo aquelas produtoras de saber por excelência e aquelas que aplicam esses saberes. Pode-se dizer que o Design como atividade humana que produz e aplica saberes, sofre diretamente as conseqüências do especialismo.

A interdisciplinaridade deve ser entendida como uma forma de conscientização e não apenas como uma atitude diante da vida.

Nos anos 70 a interdisciplinaridade nas ciências passou de uma fase de definição e explicação terminológica para uma fase de discussão do seu lugar nas ciências humanas e na educação nos anos 80 . Hoje, no plano teórico, os estudos fundamentam-se na ética e na antropologia e no plano prático, os projetos reivindicam uma visão interdisciplinar.

O uso excessivo do termo interdisciplinaridade gerou sua banalização. Ele não possui um único sentido epistemológico. A significação do neologismo nem sempre é compreendida da mesma forma por todos. Ela muda de acordo com o enfoque teórico adotado.

Mas o conhecimento interdisciplinar ganha a cada dia maior destaque no meio dos debates epistemológicos. Isso porque se torna cada vez mais difícil negar o estado lamentável de esfacelamento do conhecimento científico e as conseqüentes dificuldades no seu ensino.

Existe uma disposição já declarada de muitos intelectuais, de ao menos tentar um diálogo mais promissor entre as diversas disciplinas científicas. As disciplinas apresentam-se como compartimentos epistemológicos muitas vezes fechados 
em si mesmos. O fato delas assim se apresentarem, já era anunciado como uma manifestação de condição patológica do saber (JAPIASSU, 1976).

A crescente especialização, gerada pelos processos adotados para a produção dos novos avanços na ciência e na tecnologia, culminou numa fragmentação do corpus epistemológico.

O especialista sabe, a cada dia que passa, mais sobre menos. José Ortega y Gasset ao referir-se aos especialistas, os denominou de "novos bárbaros": [...] o novo bárbaro é, na verdade, o profissional mais sábio que nunca, mas o mais inculto também - é o engenheiro, o médico, o advogado, o homem de ciência dos nossos dias (GASSET, 1946, p.32).

Edgar Morin (2001, p. 15), bem lembra que a [...] unidade complexa da natureza humana é totalmente desintegrada na educação por meio das disciplinas, tendo-se tornado impossível aprender o que significa ser humano.

Ao mesmo tempo em que o mundo foi contemplado pela técnica, angariando um avanço significativo no aspecto material, levou o homem a ver o mundo de maneira compartimentalizada, separando a ciência da ética, a razão do sentimento, a ciência da fé, e, em especial, separando mente e corpo. (BEHRENS, 2000, p.20).

O nível que o especialismo e a fragmentação do conhecimento vêm alcançando exige uma revisão dos pressupostos nos quais se baseiam. Saber muito de pouco é resultado de uma inteligência também despedaçada. O sujeito inteligente opõe à "cegueira" gerada pelo especialismo, um conhecimento mais abrangente e generalista exigido para a compreensão das situações complexas. Este, não é necessariamente um conhecimento profundo, normalmente limitado. Para a sabedoria do ser humano, a profundidade do conhecimento deverá estar aliada a sua abrangência.

O conceito vem se desenvolvendo também nas ciências da educação e pode ser identificada como um caminho promissor para a formação integral do ser humano. Porém, o ensino e a pesquisa baseados numa proposta interdisciplinar são difíceis de serem levados a cabo. Isso porque o desconhecimento, a ignorância e a falta de compreensão de que o novo só é possível pela promoção de interpenetrações e interações disciplinares, ainda fazem parte da cultura das instituições de ensino.

A interdisciplinaridade é uma forma de pensar. Piaget sustentava que a interdisciplinaridade seria uma forma de se chegar à transdisciplinaridade, etapa que não ficaria na interação e reciprocidade entre as ciências, mas alcançaria um estágio onde não haveria mais fronteiras entre as disciplinas. (INSTITUTO PAULO FREIRE, 2011).

Mas as ciências ainda são ensinadas nas escolas de forma dogmática, tornam-se alienadas, pois são enfocadas de maneira estanque, como se fossem independentes. A "cegueira" intelectual gerada pelo saber especializado distancia este saber das condições sócio-históricas que lhe deram origem (3). Com isto, perde-se a noção da realidade próxima.

Levado ao extremo o especialismo pode gerar "bárbaros" que não mais sabem nem mesmo aquilo que acreditavam saber. $O$ conhecimento tratado como especialidade torna-se falso produto de consumo e símbolo do poder. O acesso a ele é, sob este ponto de vista, uma questão de concorrência e de propriedade privada epistemológica.

A organização de categorias dentro das diversas áreas do conhecimento, cobertas pelas 
A interdisciplinaridade e o ensino do design

ciências caracterizam o que se convencionou chamar de disciplinas.

A organização disciplinar foi instituída no século XIX, notadamente com a formação das universidades modernas; desenvolveu-se, depois, no século $X X$, com o impulso dado à pesquisa científica; isto significa que as disciplinas têm uma história: nascimento, institucionalização, evolução, esgotamento, etc.; essa história está inscrita na da Universidade, que, por sua vez, está inscrita na história da sociedade. (MORIN, 2002, p. 105).

A supremacia do conhecimento fragmentado de acordo com as disciplinas impede freqüentemente de operar o vínculo entre as partes e a totalidade, e deve ser substituída por um modo de conhecimento capaz de apreender os objetos em seu contexto, sua complexidade, seu conjunto. (MORIN, 2001, p.14).

Para o docente, numa concepção disciplinar, o trabalho realizado dentro dos limites da disciplina, devidamente balizados, evita a sua exposição a maiores doses de incerteza, por outro lado, assume um papel de reprodutor do conhecimento.

A visão fragmentada levou os professores e os alunos a processos que se restringem à reprodução do conhecimento. As metodologias utilizadas pelos docentes têm estado assentadas na reprodução, na cópia e na imitação. A ênfase do processo pedagógico recai no produto, no resultado, na memorização do conteúdo, restringindo-se a cumprir tarefas repetitivas que, muitas vezes, não apresentam sentido ou significado para quem as realiza. (BEHRENS, 2000, p.24).

Quebrar o invólucro criado pelo especialismo, em torno do conhecimento, provoca medos e desconfianças. É compreensível, pois as novidades que podem resultar deste rompimento com o estado vigente incomodam e provocam reações de temor. Elas questionam o "já dominado" e o "já aceito". Aos olhos do especialismo, é mais apropriado cultivar o espírito conservador do que aventurar-se no desconhecido. Mas questionar é dar passagem a outras "verdades". Pode-se dizer que o conhecimento como busca dessas verdades deve ser constantemente questionado; as verdades resultam das conclusões das polêmicas que as geraram.

O conhecimento, sob este ponto de vista, não se dá pela mera transmissão dos saberes já adquiridos. A mera transmissão resultaria fatalmente na reprodução. $O$ ensino deve então centrar seus esforços nos meios que permitam ao aluno a apropriação do conhecimento e acima de tudo, a sua construção ou reconstrução. Assim então, o ensino deveria aperfeiçoar os seus recursos pedagógicos para viabilizar esta tarefa. Ensinar sob este ponto de vista é, de fato, possibilitar aprendizagens.

Neste caso a interdisciplinaridade está relacionada ao conceito de autonomia intelectual e moral. Ela serve-se do construtivismo e serve a ele. Como teoria da aprendizagem o construtivismo entende o conhecimento como resultado da interação entre o sujeito e o meio. O papel do sujeito é primordial na construção dos conhecimentos e saberes e a relação entre a autonomia intelectual e interdisciplinaridade é imediata. No construtivismo piagetiano o sujeito não espera que o conhecimento lhe seja transmitido. É ele que aprende por meio de suas próprias ações sobre o mundo. Ele tem autonomia e constrói suas próprias categorias de pensamento ao mesmo tempo em que organiza o seu mundo.

Piaget (1973) conceituou a interdisciplinaridade contrapondo-a aos conceitos de multidisciplinaridade e de transdisciplinaridade. Para ele, a interdisciplinaridade corresponderia ao intercâmbio recíproco entre as partes, capaz de gerar enriquecimento mútuo. A 
Antonio Martiniano Fontoura

multidisciplinaridade implicaria na solução de um problema por meio do envolvimento de diferentes disciplinas, havendo apenas empréstimos, porém sem enriquecimento mútuo. $\mathrm{A}$ multidisciplinaridade é o ponto de partida para a interdisciplinaridade. A transdisciplinaridade, por sua vez, promove a integração total entre disciplinas, com eliminação de fronteiras entre elas. Para Piaget haveria um momento na história do pensamento humano em que a interdisciplinaridade alcançaria um nível tão intenso de conexão que ultrapassaria o simples diálogo e chegaria num nível mais elevado de interação. $O$ ensino transdisciplinar seria para Piaget o grau mais aprofundado do interdisciplinar.

Pode-se verificar um anacronismo entre a produção do conhecimento e o que é ensinado nas instituições escolares. As escolas comodamente preferem ensinar o já sabido e reproduzir o já estabelecido - postura reprodutivista e conteudista. Com certeza, não será esta a escola que mudará o destino da humanidade. O verdadeiro educador não pode ser um cúmplice, um reprodutor dos ditames e cumpridor das normas que cerceiam a abertura do espírito e negam ao educando o cultivo de um senso mais aguçado da realidade humana.

O especialista, assim como o educador tradicional, não duvida de si mesmo. Não questiona os seus conhecimentos. Protege-se atrás da sua especialidade por meio dos ritos e hermetismos criados através das suas práticas. Costuma ser impositivo e quase sempre autoritário.

O verdadeiro educador não impõe suas verdades. O conhecimento para ele não é algo que se transmite, mas sim, que se busca e se constrói. É esse espírito que deve ser cultivado no educando e especialmente nos estudantes de Design. A sede de conhecimento, o prazer da descoberta, a atitude criativa, a insatisfação constante e fecunda, são algumas características desse espírito. Ensinar, sob esta perspectiva, é levar o educando a compreender que é ele próprio que se educa. É ele que aprende. É ele que acessa e pode se apropriar do já sabido e consolidado pela humanidade. Ensinar passa a ser um processo de autoconstrução ou de auto-reconstrução. Trata-se de um processo que nada tem a ver com a mera transmissão de informações ou repasses de conteúdos. É um processo de apropriação e construção de conhecimentos.

Porém, a resistência a interdisciplinaridade ainda persiste no panorama escolar. No campo do ensino do Design a prática parece não fugir à regra. $O$ trabalho interdisciplinar raramente tem se consolidado no seu ambiente acadêmico fortemente marcado pela organização disciplinar e pela estrutura acadêmica departamental.

Ao bem da verdade o que é colocado em dúvida é uma concepção do saber e do seu ensino.

A interdisciplinaridade apresenta-se como uma nova forma de organização do conhecimento e dos processos pedagógicos. Ela propõe uma nova ordem para o horizonte epistemológico.

A interdisciplinaridade visa a garantir a construção de um conhecimento globalizante, rompendo com as fronteiras das disciplinas. Para isso, integrar conteúdos não seria suficiente. Seria preciso uma atitude e postura interdisciplinar. Atitude de busca, envolvimento, compromisso, reciprocidade diante do conhecimento. (INSTITUTO PAULO FREIRE, 2011).

Em nenhum momento esta nova forma de organização, nega a disciplina como forma de organização do conhecimento; o que ela prega é uma interação e integração desejável e necessária entre elas - ciências/disciplinas - sempre que possível. Vem ao encontro das concepções holísticas (CAPRA, 2001) onde o conhecimento é considerado como um todo 
A interdisciplinaridade e o ensino do design

que representa mais que a simples soma das partes. Trata-se da crença de que as relações estabelecidas entre as partes são tão ou mais significativas que a própria totalidade.

A interdisciplinaridade, quando colocada em prática, pressupõe a interação de conceitos bem como a interação metodológica para então atingir a interação entre disciplinas. Assim, pode-se tomar como referência a conceituação desenvolvida por Ivani Fazenda que diz que a interdisciplinaridade é a

[...] interação existente entre duas ou mais disciplinas. Essa interação pode ir da simples comunicação de idéias à interação mútua dos conceitos diretores da epistemologia, da terminologia, da metodologia, dos procedimentos, dos dados da organização referentes ao ensino e a pesquisa. Um grupo interdisciplinar compõe-se de pessoas que receberam sua formação em diferentes domínios do conhecimento (disciplinas) com seus métodos, conceitos, dados e termos próprios. (FAZENDA, 1979, p.27).

O que parece utópico na proposta interdisciplinar é a suposta "unidade do saber". Deve-se levar em consideração que, apesar de utópica, ela serve como meta ideal de qualquer conhecimento que pretenda atender às exigências fundamentais do progresso humano e da formação integral do cidadão.

Hoje, tem-se falado muito em interdisciplinaridade, mas também se tem recusado muito as exigências interdisciplinares. Esse paradoxo é devido à ainda crescente especialização que ocupa o território do saber.

A crescente especialização ocorre pelo aprofundamento, cada vez maior, em questões cada vez mais específicas do conhecimento. Apesar das virtuais vantagens da divisão do campo do saber, ele fatalmente leva a uma perda da visão do todo.

Segundo Morin, é necessário desenvolver a aptidão natural do espírito humano para situar todas essas informações em um contexto e um conjunto. É preciso ensinar os métodos que permitam estabelecer as relações mútuas e as influências recíprocas entre as partes e o todo em um mundo complexo (MORIN, 2001, p.14).

No lugar de práticas interdisciplinares é muito comum encontrar-se nas escolas, práticas pluridisciplinares, ou seja, o "encontro de duas ou mais disciplinas, com objetivos múltiplos, com certa relação entre si, com certa cooperação, mas sem coordenação dessas relações" (FAZENDA, 1999, p. 31; PETRAGLIA, 1993, p. 33). Estas relações acontecem meio que ao acaso e normalmente de forma individualizada. De qualquer maneira, muitos docentes já descobriram o espírito interdisciplinar e seu valor para uma prática mais humana. O interdisciplinar não é algo que se ensine ou que se aprenda é algo que se toma consciência e se concretiza através da mudança de atitude, diante do processo educacional.

Couto (1997) afirma que é esta

[...] mudança de atitude, que possibilita o conhecimento, por parte do indivíduo, dos limites de seu saber para poder acolher contribuições de outras disciplinas. Interdisciplinaridade deve ser, pois, entendida antes de tudo, como atitude, pautada pelo rompimento com a postura positivista de fragmentação, visando a compreensão mais ampla da realidade. Através desta postura é que ocorre a interação efetiva, sinônimo do interdisciplinar .

Para o trabalho interdisciplinar, assim como para o trabalho no campo do Design, são essenciais: a curiosidade, a abertura para o novo, o sentido de aventura e de busca e o uso da intuição. Adotar uma atitude interdisciplinar não significa recusar por completo o 
Antonio Martiniano Fontoura

especialismo, mas sim, o dogmatismo dos saberes por ele estabelecido. O questionamento dos conhecimentos passa a ser uma constante sob este ponto de vista.

\section{O Design}

O Design é por natureza interdisciplinar. Há nele implícita uma vocação interdisciplinar, pois se trata de uma área propícia para o trabalho conjunto com outras áreas de conhecimento. Uma das características de uma atividade de Design é o envolvimento de inúmeros conhecimentos de domínios distintos. Assim, não é raro encontrar-se um designer caminhando por áreas de conhecimentos que a princípio não lhe dizem respeito.

A interdisciplinaridade vem ao encontro das exigências desta atividade, pois ao projetar, além de levar em consideração as inúmeras condicionantes técnicas, o designer considera também o universo de necessidades dos usuários. Isso implica um acervo de conhecimentos oriundos de diversas áreas, entre elas: da antropologia, da psicologia, da sociologia, da arte, da ergonomia, da semiótica, da tecnologia, da ciência dos materiais, das técnicas de representação, da economia, da administração, do marketing, da proxêmica, da informática, aplicados simultaneamente na criação e no desenvolvimento de projetos, sejam eles na área gráfica, na digital, na moda, na moveleira, na de jóias, na automobilística, na calçadista, na de interiores.

O desenvolvimento de projetos e as atividades de Design também podem ser caracterizados como processos geradores de conhecimentos, pois freqüentemente fazem uso da pesquisa como instrumento de ação. Além de revelar a íntima relação entre o ensino e a pesquisa, a interdisciplinaridade pode esclarecer as diferenças entre a pesquisa pura e a pesquisa aplicada, entre a teoria e a prática. Ela acaba transformando a sala de aula - espaço para a ação -, num lugar onde se constrói criticamente novos conhecimentos a partir do domínio e confrontação com os já existentes.

É importante salientar que a atitude interdisciplinar estabelece uma nova relação entre docentes e discentes e que são pertinentes ao ensino do Design:

a.Não há hora nem data marcada para se apreender. $O$ ensino e a aprendizagem extrapolam os limites e horários das aulas. Ultrapassam os espaços físicos da escola.

b.É o indivíduo e não uma coletividade amorfa que apreende, trata-se de uma relação direta e pessoal com a aquisição e produção do saber.

c.O conhecimento é uma totalidade, é apreendido individualmente, mas o todo é muito mais do que a soma das partes.

d.O ensino e a aprendizagem tornam-se significativos quando inseridos no projeto de vida daquele que aprende. Aprende-se quando se está envolvido emocionalmente e racionalmente com o processo de reprodução, produção, recriação e criação do conhecimento. A biografia daquele que apreende é, portanto, a base do seu projeto de vida e de aquisição do conhecimento e de novas atitudes.

E que a metodologia do trabalho interdisciplinar sempre implica (INSTITUTO PAULO FREIRE, 2011):

- a integração de conteúdos;

- a passagem de uma concepção fragmentária para uma concepção unitária do conhecimento;

- a superação da dicotomia entre ensino e pesquisa, considerando o estudo e a pesquisa, a partir da contribuição das diversas ciências; e 
A interdisciplinaridade e o ensino do design

- a promoção do processo de ensino-aprendizagem centrado numa visão de que se aprende ao longo de toda a vida.

Parecem claras as vantagens da possível aplicação da interdisciplinaridade no ensino, mas como já foi mencionado anteriormente, ela depara-se com resistências. Muitas delas são hábitos arraigados, estruturas administrativas e acadêmicas lentas e presas às tradições, presença de preconceitos, falta de autonomia, falta de preparo e insegurança dos educa-dores, que se transformam em verdadeiras barreiras para qualquer iniciativa diferente das triviais. Caracterizam-se como obstáculos de origem epistemológica, institucionais, psico-sociológicas e culturais.

Qualquer mudança no contexto educacional representa necessariamente, uma renovação no espírito pedagógico, demanda uma nova postura e uma nova consciência.

O ensino com base no especialismo deve dar lugar a um ensino aberto a pluralidade, ao espírito inovador, à imaginação criadora e inventiva. Além da análise e da síntese, é necessário desenvolver a capacidade de síncrise (4) no educando. O conhecimento fragmentado deve ser reorganizado. A interdisciplinaridade representa uma opção, um caminho, uma alternativa para esta reorganização.

Ao defender-se a interdisciplinaridade e o generalismo na formação do designer, devese deixar claro que não se sugere aqui, a possibilidade de um curso único de formação de designers generalistas - apesar de haver algumas experiências pedagógicas muito interessantes neste sentido mundo afora - ou um bacharelado capaz oferecer uma formação generalista capaz de atender as demandas da sociedade fazendo uso das atuais estruturas e organizações acadêmicas, disciplinares e departamentais presentes nas nossas instituições de ensino superior. O que se propõe e defende-se é uma formação ampla, geral e sólida para todo e qualquer designer (Gráfico, de Produto, de Moda, Digital, de Interiores, etc.). Defende-se para o Design uma formação técnica-científica consistente e de acordo com as demandas sociais, porém sempre muito humana, reflexiva, ativa e integradora, sem que nunca se perca a noção do que é "Ser Humano".

É importante não confundir a interdisciplinaridade com a falta de disciplina. Ao contrário da "indisciplina", a interdisciplinaridade, parte da disciplinaridade e busca estabelecer uma nova ordem. Ensinar e pesquisar são indissociáveis, significam nessa perspectiva, a busca da construção coletiva de um novo saber, em que este não é privilégio de apenas alguns.

Objetivar uma formação mais generalista para designers, mantendo-se currículos eminentemente disciplinares "engessados" - rígidos - ainda comuns nos cursos brasileiros de Design, torna este objetivo praticamente inalcançável. São necessárias novas concepções curriculares - ainda disciplinares -, porém mais flexíveis e que permitam a integração de conteúdos, conhecimentos e experiências; a liberdade de escolha e orientação profissional; e o respeito às potencialidades e aptidões naturais de cada educando.

Promover uma formação e realizar uma prática interdisciplinar no campo de Design é um desafio aos docentes e às instituições brasileiras, ainda mais quando se está sujeito a algumas determinações:

- legais - entre elas, as Diretrizes Curriculares Nacionais (CNE Res. n005/2004), cargas horárias mínimas, integralização e duração de cursos (CNE Res. no02/2007) e as determinações compulsórias de mudança de denominação dos bacharelados em Design (2010);

- estruturais - a inadequação de instalações, os acervos bibliográficos insuficientes, a falta de laboratórios e oficinas e o acesso limitado às novas tecnologias de produção e educacionais;

- econômico-financeiras - as dificuldades na manutenção financeira do sistema

Projética Revista Científica de Design I Universidade Estadual de Londrina I V.2 I N.2 I Dezembro 2011 
educacional, a não priorização e a falta de investimentos na área;

- de recursos humanos - a formação docente deficitária e a falta de incentivo institucional a sua qualificação (5), as baixas remunerações e falta de planos de carreira, a relação professor/aluno inadequada e o preparo dos alunos ingressantes aquém do desejado para o ensino superior;

- acadêmico-administrativas - as organizações curriculares rígidas, hierárquicas e com pré-requisitos, a oferta restrita de disciplinas nos sistemas e o predomínio de uma visão ainda conflituosa entre a promoção de produções teóricas e práticas nas escolas de Design; e

- contextuais - a falta de integração entre o mundo acadêmico e o profissional.

Promover uma formação interdisciplinar é também uma maneira de propiciar a formação mais integral do ser humano e do cidadão - elemento ciente da sua importância e condição no mundo.

A concepção interdisciplinar se opõe à positivista, compartimentada e fragmentada. Vale lembrar que ela, contraditoriamente caiu na armadilha que queria ter evitado e num determinado sentido, acabou também se especializando.

No campo da educação acabou tendo um desenvolvimento muito particular. A pedagogia interdisciplinar propõe a construção de uma instituição decisiva na formação integral do cidadão. A articulação dos saberes, dos conhecimentos, das vivências, da instituição com a comunidade e como o meio ambiente, tornou-se o principal objetivo da proposta. $\mathrm{O}$ trabalho solidário e coletivo almejado pela interdisciplinaridade deverá ser marcado por uma visão geral da educação, num sentido progressista e acima de tudo libertador.

\section{Notas}

* Este artigo foi elaborado com base num texto originalmente escrito como parte da tese de doutoramento apresentada pelo autor no Programa de Pós-Graduação em Engenharia da Produção - Gestão Integrada do Design, na Universidade Federal de Santa Catarina, em 2002 e que apesar de ter sido concebido no início da década passada permanece ainda muito atual e aparentemente muito pertinente ainda mais neste momento quando se impõe a adoção de uma única denominação para todos os cursos de bacharelado em Design neste país.

** Graduado em Desenho Industrial pela PUCPR, licenciado em Desenho (Esquema I) pelo antigo CEFET-PR, Pós-Graduado Metodologia do Ensino Superior e Mestre em Educação pela PUCPR, e Doutor em Engenharia da Produção pela UFSC. É professor nos cursos de graduação em Design na PUCPR, no curso de Tecnologia em Design Gráfico na UTFPR e no PPGDesign na UFPR (Mestrado em Design).

${ }^{1}$ A disciplinaridade ou multidisciplinaridade refere-se a um modelo fragmentado no qual há a justaposição de disciplinas diversas, sem relação aparente entre si.

${ }^{2} O$ termo interdisciplinaridade possui diversas acepções e é utilizada para designar diversas situações de inter-relação entre duas ou mais disciplinas. A interdisciplinaridade representa uma nova concepção de divisão do saber que enfatiza a interdependência, a interação, a comunicação existente entre as disciplinas e busca a interação do conhecimento num todo harmônico e significativo. Um estágio mais desenvolvido no qual todas as disciplinas seriam coordenadas num sistema lógico de conhecimentos, com livre trânsito de um campo de saber para outro é denominado de transdisciplinaridade. (FAZENDA, 1999)

${ }^{3}$ Como lembra ARISTÓTELES (385-322 a.C.), nada é melhor para se compreender um tema em sua extensão do que historicizá-lo.

${ }^{4} \mathrm{~A}$ síncrise é aqui entendida como reunião de idéias distintas, visão conjunta de uma totalidade complexa; ou ainda a fusão de elementos diferentes e até antagônicos. 
A interdisciplinaridade e o ensino do design

${ }^{5}$ Deve-se fazer uma ressalva em relação aos incentivos e investimentos realizados por organizações como a CAPES e CNPq no que se refere à oferta de bolsas para a formação de doutores no exterior nos últimos anos, com o intuito de qualificar e consolidar de grupos de pesquisadores no Brasil.

\section{Referências}

BEHRENS, M. A. O paradigma emergente e a prática pedagógica. Curitiba: Champagnat, 2000.

CAPRA, F. O ponto de mutação. São Paulo: Cultrix, 2001.

COUTO, Rita Maria de Souza. Movimento interdisciplinar de designers brasileiros em busca de educação avançada. 1997. Tese. (Doutorado em Educação) - Pontifícia Universidade Católica do Rio de Janeiro, Rio de Janeiro, 1997.

FAZENDA, I. C. A. Integração e interdisciplinaridade no ensino brasileiro, efetividade ou ideologia. São Paulo: Loyola, 1979. . Interdisciplinaridade, um projeto em parceria. São Paulo: Loyola, 1999.

GASSET, J. O. Y. Missão da universidade. Porto: Seara Nova, 1946.

INSTITUTO PAULO FREIRE. Inter-transdisciplinaridade e transdiciplinadidade. Disponível em:<http://www.inclusao.com.br/projeto_textos_48.htm>. Acesso em: 26 maio. 2011.

JAPIASSU, H. Interdisciplinaridade e patologia do saber. Rio de Janeiro: Imago, 1976.

MORIN, E. A cabeça bem feita. Repensar a reforma repensar o pensamento. Rio de Janeiro: Bertrand Brasil, 2002.

. Os sete saberes necessários à educação do futuro. São Paulo: Cortez, 2001.

PETRAGLIA, I. C. Interdisciplinaridade: o cultivo do professor. São Paulo: Pioneira , 1993.

PIAGET, J. Problemas gerais da investigação interdisciplinar e mecanismos comuns. Lisboa: Bertrand, 1973. 